\title{
Optimization of Assembly Line of An Eicher Tractor Unit
}

\author{
Nishant Sthapak \\ M.Tech Scholar \\ Sagar Institute of Research and Technology Excellence \\ Bhopal, M.P., India \\ nishantsthapak0@gmail.com
}

\author{
Yogesh Agrawal \\ Professor \\ Sagar Institute of Research and Technology Excellence \\ Bhopal. M.P, India \\ a80yogi@gmail.com
}

\begin{abstract}
Line balancing is about arranging a production line so that there is an even flow of production from one work station to the next. Line balancing also a successful tool to reduce bottleneck by balancing the task time of each work station so that there is no delays and nobody is overburden with their task. This thesis presents a case study on a line balancing problem in an eicher company and the study focused on assembly line. This study aims to improve the productivity and line efficiency also to recommend improvement activities based on the line balancing and analysis done in the simulation model. The simulation was done by using Tecnomatix Plant Simulation. All the data needed for the line balancing analysis was collected and a line balancing model equipped with manual calculation was done. This data gathered is then simulated in Tecnomatix Plant Simulation. Among the improvement activities conducted in order to balance the line was combining a few process into one, transformation from manual process to mechanization, and removing waste from the line. Throughout the study, three layouts were proposed. Among these three layouts only one will be proposed to the company. The layout proposed has a better line efficiency and rate of productivity.
\end{abstract}

Keywords: management, organization, production system, plant simulation, digital manufacturing, material flow.

\section{I.INTRODUCTION}

"Tecnomatix" is the complex portfolio of digital solutions for the production process that unites all production disciplines with the assembly processes of engineering products, from design and planning to simulation and process verification. . With the "Teamcenter" product, it is one of the most universal products for manufacturers on the market.
A wave of massive innovation in Germany is known as the fourth industrial revolution for 260 years. It is based on the use of advanced information and communication technologies in all industrial sectors of management, processing and delivery of products to customers. The ability to obtain the amount of data on real processes and their treatment offers researchers the ability to create a virtual image of industrial processes. This virtual image of reality is provided by experimenting with the real system in a virtual environment without the risks that would jeopardize the functioning of real systems. When the real world and the virtual world transmit digital models and techniques that provide tools for dynamic analysis such as simulation, emulation and meta modelling, there is a completely new kind of environment. This type of environment has become a basic idea of Industry 4.0. Industrial philosophy has become a blow to the German economy. Part of this philosophy is also a digital business. It is an information technology that replaces the model of the real world. Industry 4.0 is the theme of the future of digital businesses.

At present, manufacturing companies have to adapt to changing customer demands, which causes problems in the planning of production logistics and material flow. Internal information systems often cannot predict the exact needs and personnel, inventory, number of vehicles, footprint and other parameters as conditions change. From a business point of view, you need a planning tool that takes changes into account and provides results that indicate how you should behave like a logistics system.

In the background, planning tools, consumption standards, working time analysis or other studies are developed. The task is to define the user input parameters, e.g. Production schedule, lot size, etc. 


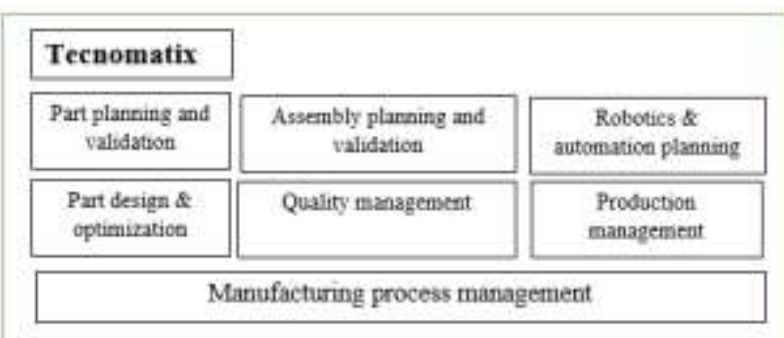

Figure 1 Tecnomatix and its characteristics

According to solution is Tecnomatix used for:

- Planning and verification of component.

- Planning and verification of assembly procedures.

- Planning in the field of robotics.

- Design and optimization of plants.

- Quality management.

- Production management.

- Production process management.

\subsection{APPLICATION OF TECNOMATIX}

Installation simulation the modeling of technological processes and the creation of simulation models of real production systems of Tecnomatix Plant Simulation can be performed in 2D and 3D environments. Modeling in a 2D environment shown in Figure 1 applies to complex optimization problems mainly related to the timing of the technological process, ie the analysis of the production process from time to time (production time, additional and additional times, times of intermediate ends, production cycles).

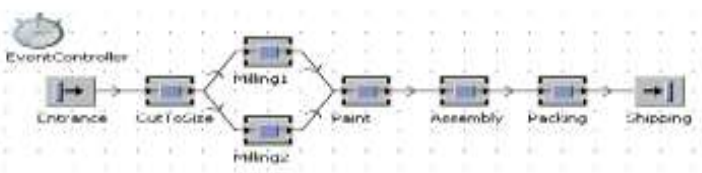

Figure 2 - Modeling of process planning in 2D environment

Application of Tecnomatix Plant Simulation to the process plan model for "corpus" production unit in the work area with two milling machines - milling1 and milling2. The main objectives of the simulations are to minimize processing and installation times, maximize utilization, minimize inventory and increase delivery times. The following data were used as basic parameters for the simulation and modeling process with the Tecnomatix Plan Simulation program system: production process plan for "corpus" parts (sequence of operations, production time, additional time and list of machines) and number of units per year.

\section{LITERATURE REVIEW}

Borojevic et al. [1] In this document, the planning of the process has been modeled and simulated in concrete conditions. This program system was applied in a $2 \mathrm{D}$ and $3 \mathrm{D}$ environment and the optimal production parameters were also determined. The construction of production systems from the point of view of the resources needed to carry out the production process for several years constitutes an important set of technical tasks. In the context of the design of production systems, in addition to the planning of the process planning, it is necessary to determine the regulatory parameters with which the efficiency of the production process reaches a high level. Rajashekar Patil et al. [2] In this study, production systems are one of the key applications of simulation, which has been used successfully to facilitate the design of new production facilities and to evaluate the proposed improvements to existing systems. Many simulation tools are available on the market.

Olivier Martin et. al. [3] This report describes how the simulation of discrete events can be used to optimize the production of electronic assembly lines. At the moment, many production decisions are based on workers' experience. However, understanding the parameters that influence production is a difficult task, especially for systems with a variety of products. Exploitation could be improved by analyzing bottlenecks and their impact on the overall capacity of the line.

A Gatsou et al. [4] This article produces fitness equipment commonly used in gyms. Some variants of these machines are produced in stock, but the total delivery time was considered too long. Therefore, although the structure of the production system was considered stable, it was examined using discrete event simulation software to validate the initial explanations and also to test new control rules.

\section{III.OBJECTIVES}

Main objectives of this project work are described below:

- Design a concept of the digital factory and its utilization.

- Get acquainted with the process simulation software from Siemens.

- Model a 2D simulation of production processes in simulation software. This simulation will be adapted to be used with external controller.

- Find a way how to connect simulation to an external controller performing the control of the transfer line

- Select a suitable method to define to simulated transfer line.

- Optimize the machining time to improve the production line of plant. 
- To improve the overall productivity of the plant.

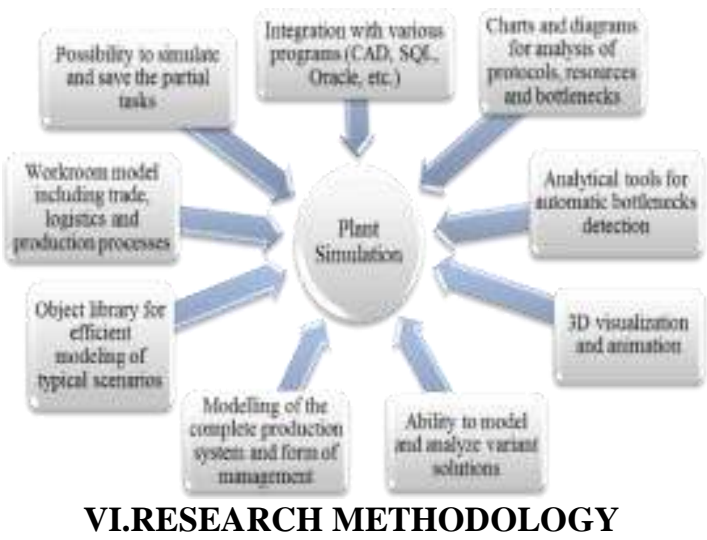

The briefly describes basic terms relating to the digital factory environment, which is called Siemens Tecnomatix.

\section{1) Utilization of The System Module Plant Simulation}

Plant Simulation allows creating digital models, which are then used for simulation of specific conditions within the production process while changing selected parameters and characteristics of the process.

Figure 3: Modules of Tecnomatix considering the utilization

Simulation of various set conditions of the production process allows optimizing before the real starting, the inputs and outputs of the production process. During the optimization of the selected production process we decided for Plant Simulation, because of its ability to create plans or scenarios for the future in the planning phase of the project to the benefit of different production systems models. This module allows the hierarchical construction of models in 2D and 3D interface, with respect to production, storage and distribution mutually linked chains of objects. The possibilities of Plant Simulation utilization

During simulating the production process is evaluated the achieved output, respectively the operation of the production system during certain period, on the basis of statistical data. The performance characteristics of the production systems can be summarized as follows:

- Utilization of resources,

- Stock size in terms of the number of pending parts,

- Machine failure statistics,

- Machine blocking time,

- Return on investment,

- cost indicators of production,

- the amount of scraps,

- the number of parts that were faulty, respectively require repair,
- trouble-free operation,

- time during which work is stopped due to device inactivity,

- waiting time of the product before workplace,

- monitoring of production performance, which indicates, how many products are produced during the simulation,

- continuous production time for a particular product,

- the amount of inventories and work in process of production.

Figure 4: Examples of Plant Simulation exploitation

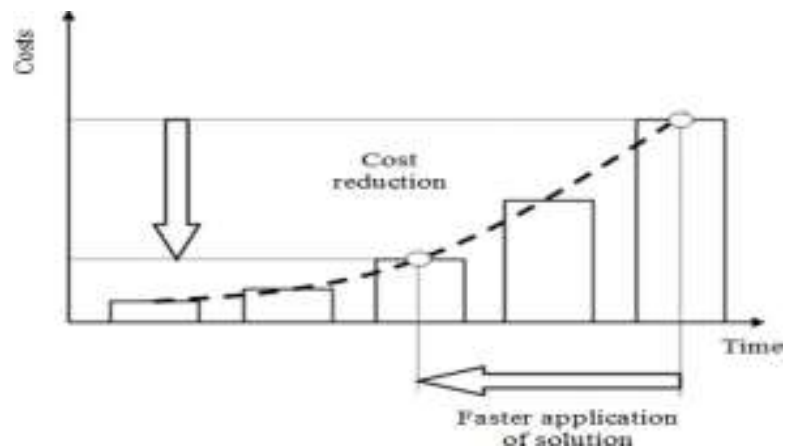

Figure 5: Cost savings resulting from the early utilization of Plant Simulation

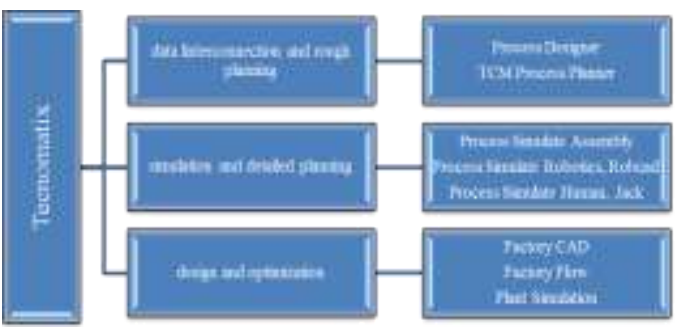

2) Product for Simulation Process

Products we have chosen for the simulation process are tapered roller bearings. Fig. 4 shows the tapered roller bearing with its main parts. The components, from which they consist, are:

- inner ring,

- rolling element (in this case cones),

- outer ring (in the case of tapered roller bearings it is separable),

- Ball cage (the purpose is to avoid contact/friction of individual cones with another cones).

Their typical characteristic, compared to other types of bearings, is the ability to transmit big axial and radial forces simultaneously

\section{3) Assembly Methods}

Before going to Assembly line we have to familiar to the Assembly line and terms related to it. There are two primary methods of assembly in the industry, which are 
bench assembly and line assembly. In bench assembly, the work-piece stays stationary on a bench; all required parts and equipment for assembly are brought to the bench and assemblers move around the bench to perform the assembly. Line assembly is an assembly method where work-pieces move through a sequence of stations for assembly one piece at a time. An assembly line is the production system in which assembly stations are organized in a serial layout and line assembly method is applied. At Eicher Engines line assembly is adopted for assemble engines.

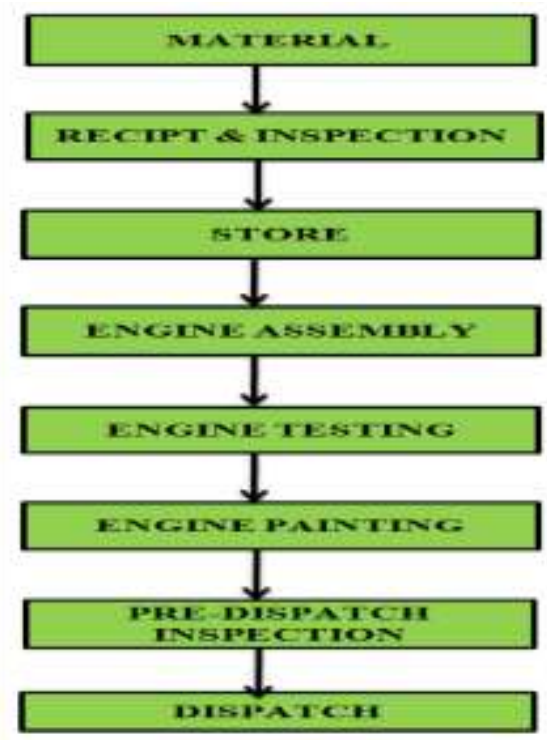

Figure 6: Engine Assembly Process Flow Chart

\section{4) Assembly Line Balancing}

Balancing an assembly line indicates distribution of total workload of the line among each station at the line equally so that idle times and the difference between the idle times at different stations are as low as possible. The key here is to balance the workload of operators at every station; reducing operator idle times at stations over a takt means reduction of unused station capacity, which is the expected result of line balancing and which helps minimization of losses and costs. In other words possible results of an assembly line balancing process might be maximized efficiency, minimized time to finish a process, or minimized number of work stations necessary within a certain time frame. Each manufacturing process might be quite different from another, so a company balancing unique workloads must work within the constraints and restrictions affecting its specific assembly line.

\section{5) Assembly Line Methods}

Depending on the production strategy, assembly lines can be designed such that assembly of different products can be held at same line. According to the diversity of products assembled at the line, assembly lines are divided into three main categories:-

1. Single Model Assembly Lines

2. Mixed Model Assembly Lines

3. Multi Model Assembly Lines

Single-Model Assembly lines have been used in single type or model production only. There are large quantities of the products, which have the same physical design on the line. Here, operators who work at a workstation execute the same amount of work when a sequence of products goes past them at a constant speed.

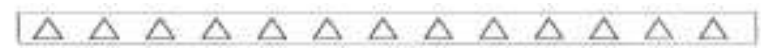

Figure 7 Single Model Assembly lines

Mixed-Model Assembly lines are usually used to assemble two or more different models of the same product simultaneously. On the line, the produced items keep changing from model to model continuously.

\section{$\square \triangle \square \circlearrowright \circlearrowright \triangle \square \circlearrowleft \square \triangle \triangle \square \triangle \circlearrowright \square$}

Figure 8 Mixed-Model Assembly lines

Multi-Model Assembly lines. Several (similar) products are manufactured on one or several assembly lines. Because of significant differences in the production processes, rearrangements of the line equipment are required when product changes occur. Consequently, the products are assembled in separate batches in order to minimize set-up inefficiencies. While enlarging batch sizes reduces set-up costs, inventory costs are increased.

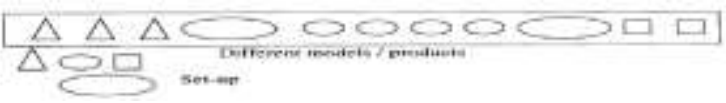

Figure 9 Multi-Model Assembly lines

\section{6) Parameters Related to Assembly Line Balancing:-}

\section{Takt Time}

Assuming a product is made one unit at a time at a constant rate during the net available work time, the takt time is the amount of time that must elapse between two consecutive unit completions in order to meet the demand. Takt time can be first determined with the formula:

$$
T=\frac{T_{a}}{D}
$$

Where,

$\mathrm{T}=$ Takt time, e.g. [work time between two consecutive units] $\mathrm{Ta}=$ Net time available to work, e.g. [work time per period] 
$\mathrm{D}=$ Demand (customer demand), e.g. [units required per period]

Example:

If there are a total of 8 hours (or 480 minutes) in a shift (gross time) less 30 minutes lunch, 30 minutes for breaks $(2 \times 15$ minutes), 10 minutes for a team briefing and 10 minutes for basic maintenance checks, then the net Available Time to Work $=480-30-30-10-10=400$ minutes.

If customer demand was, say, 400 units a day and one shift was being run, then the line would be required to output at the rate of a minimum of one part per minute in order to be able to keep up with customer demand.

\section{7) Verification of Operations Lists}

Individual operations lists for the bus models of interest have been completed and verified by applying four different data gathering methods;

- Data mining

- Time studies

- Observations

- Interviews

The theoretical basis and the application of these methods are described in the following sections.

\section{a. Data Mining}

Data mining can be defined as collecting the information that will be used throughout the work to be conducted. Quality of collected information, which is defined by McGilvray. "the degree to which information and data can be a trusted source for any and/or all required uses", is the most crucial aspect of data mining since it directly affects the outcome of the project.

The data of pre-assembly operations of vehicles of interest has been collected from the summary sheets provided by the Work Preparation Group and different databases within the factory. However, encountered unconformities between different sources indicated problems with updating of the databases, which reduced the reliability of the collected data for a line balancing procedure. Therefore, having the data from these sources as the guideline, three additional data gathering techniques have been applied to complete and verify the information to be used throughout this study.

\section{b. Time Studies}

Glassey defines the purpose of time study as "to determine the time that a worker, or group of workers, should take to do a specified job at a defined level of performance." He uses the term "performance" as a rate of output expressed as an average over the working shift, and "specified job" as a job where there is a written specification that concerns standard quality to be achieved, the tools and materials to be used, the working conditions under which the job should be performed, and the method to be followed by the operator. Glassey from these definitions, it can be concluded that the primary objective of making time studies at the pre-assembly line is to determine the standard times -total time in which a job should be completed at standard performance- of assembly operations at the line.

Standard operation times for tasks held at the stations are provided by the Work Preparation Group as Standard Operation Forms (SOF). An SOF is a company-specific data sheet that includes detailed analysis of individual operations with their steps and times. For tasks that do not have this information, time studies are made at the stations by using stopwatch and applying the procedure given by Glassy, which is explained in the following section.

\section{c. Observations}

Observations have been a supplementary method to double-check the data of operations lists that was provided by the Work Preparation Group, and to make time studies for operations whose times were not recorded/updated on the summary sheets.

Observation method is also used to measure the duration of operations whose time data is missing on the summary sheets. Glassy explains how observation method can be used in standard operation time measurement and briefly divides the process into three main stages. In the preparatory stage, the observer determines the operation to be timed and its steps, and makes sure that the operator is aware of the time study and all necessary equipment for the operation is available. The second stage, which is the time study itself, is where the observer records the time of day when the measurement started, the duration of each step and evaluates the performance of the operator. In the concluding stage, the observer records the time of day that the study ended, calculates the total time of the operation and completes the summary sheet. Time measurements at the preassembly line are made by applying the procedure explained by Glassey.

\section{d. Interviews}

Interviews have been the greatest investigation tool for verification of the operations lists and provided the critical ideas that affected the decisions taken throughout this study.

Closed questions, which can be regarded as yes-no questions, were used during the initial interviews held at the line with the operator team leaders while performing 
the verification of operation lists. The purpose of those interviews was to check if there is an inconsistency with the acquired operation lists from the management and the assembly operations at the stations.

The second set of interviews aimed to receive more detailed information from the team leaders and assembly operators about operations, and to dig deeper in order to reveal as much about the limitations as possible. Being the most experienced about the operations, each of the ten team leaders were asked about indeterminate constraints that define precedence, and the operations whose times were not possible to reduce by increasing number of operators. Besides, assembly operators that were selected randomly at the line according to the complexity of the operations they handled were asked about the steps of their work and if they had any suggestions for improvement. Therefore, the prepared questions for these interviews were open, which allowed them to tell as much about the operations as possible.

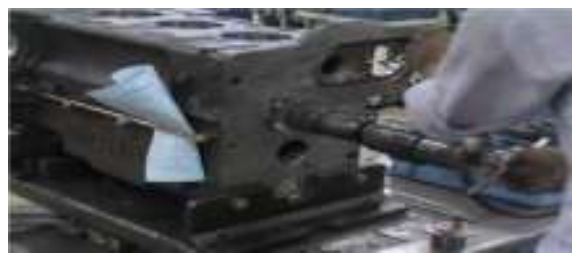

Figure 10: Crank gear pressing

\section{Line Balancing}

In order to achieve and a well-balanced assembly line, it is important to eliminate factors that cause losses; the wastes. For that purpose, of balancing time study of various stations should be carried out, method to do a particular operation should be analyzed, minimization of idle time the production system is also analyzed for determining wastes and the factors that create losses.

\section{V.RESULTS}

Assembly line is a manufacturing process (most of the time called a progressive assembly) in which parts (usually interchangeable parts) are added as the semifinished assembly moves from work station to work station where the parts are added in sequence until the final assembly is produced. By mechanically moving the parts to the assembly work and moving the semi-finished an assembly from work station to work station, a finished product can be assembled faster and with less labour than by having workers carry parts to a stationary piece for assembly. Assembly lines are the common method of assembling complex items such as automobiles and other transportation equipment, household appliances and electronic goods

\section{1) Models Related Multi Cylinder Engine Assembly Line:-}

In multi cylinder engine assembly air cooled engines are assembled, there are various types of engine model, model matrix of the multi cylinder engines are stated as below :-

Table 1 MAIN BEARING PRESSING

\begin{tabular}{|c|c|c|}
\hline S. No. & Operation 's Name & Time(s) \\
\hline 1 & Inspection of foreign materials & 18 \\
\hline 2 & Centre bolt Fitting & 24 \\
\hline 3 & Fuel Injection Pump stud Fitting & 20 \\
\hline 4 & Drain plug Fitting (2 threads) & 10 \\
\hline 5 & Suction tube Fitting (2 threads) & 2 \\
\hline 6 & Tightening of drain plug & 7 \\
\hline 7 & Tightening of Suction tube & 13 \\
\hline 8 & Adjust Torque of drain plug & 26 \\
\hline 9 & Adjust Torque of Suction tube & 13 \\
\hline 10 & Rotation of crank case $90^{\circ}$ anticlockwise & 5 \\
\hline 11 & $\begin{array}{l}\text { oil gallery plug Fitting with favicol and } \\
\text { tightening }\end{array}$ & 14 \\
\hline 12 & Torquing of oil gallery plug & 9 \\
\hline 13 & Oil gallery tube Fitting and tightening & 53 \\
\hline 14 & Oil gallery tube bolt torqueing & 15 \\
\hline 15 & History card filling & 18 \\
\hline 16 & Lubrication of crank hole \& cam hole & 7 \\
\hline 17 & Bush pressing of crank shaft \& cam shaft & 73 \\
\hline 18 & Inspection of hole after pressing & 11 \\
\hline 19 & $\begin{array}{l}\text { Shifting of engine to the next stage through } \\
\text { indexing }\end{array}$ & 14 \\
\hline \multicolumn{2}{|c|}{ Total time } & 352 \\
\hline
\end{tabular}

\section{2) Overview}

The result obtained from production failure investigation in many areas and identify is a consequence of investigation by plant simulation tool and considering real environment of transfer line.

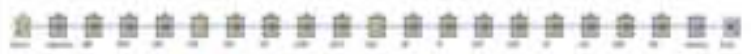

Figure 11: Single Transfer Line for Material Operation 
In a simple production line (transfer line) a model is created in simens technomatrix plant simulation where it observe the analytical results to improve the real environment in the production line as shown in above figure 5.1.

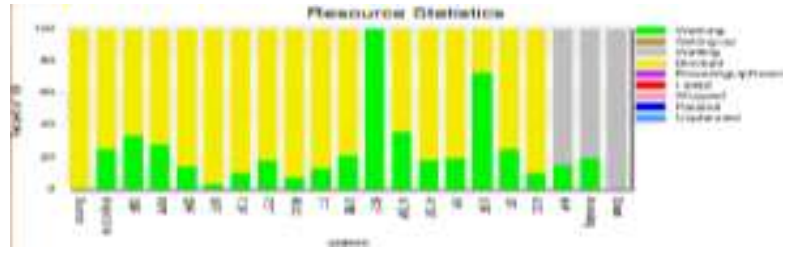

Figure 12 Chart of Single Transfer Line for Material Operation

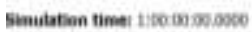

Cumulatad Statistica of the Farts which Be Drain Deleted

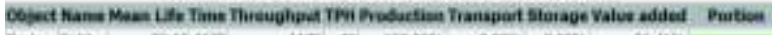

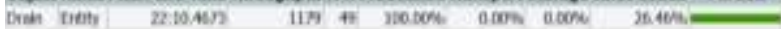

The analysis is done on the single transfer line where the model is created here there is a source and the number of process in the single transfer line and which is ending at drain now rename it as the process which needed to create by renaming the object as the source as the raw material and other as process by the help of event controller has to be drawn for the analysis the whole process and it set for the 1 day in this model as (1:0:0:0) it also show the simulation summary report and the simulation speed also be controlled by the help of it and the results of statistics report show that and adding any processing time in this model.

TABLE 2 CRANK SHAFT FITMENT

\begin{tabular}{|c|c|c|}
\hline \multicolumn{3}{|c|}{ Station No. -02 (CRANK SHAFT FITMENT ) } \\
\hline $\begin{array}{l}\text { S. } \\
\text { No. }\end{array}$ & Operation 's Name & Time \\
\hline 1 & thrust washer fitment inside crank case & 21 \\
\hline 2 & F.I.P. stud tightening & 10 \\
\hline 3 & cap fitment on crankcase with anabond & 22 \\
\hline 4 & clean cavities of crank shaft through air gun & 17 \\
\hline 5 & $\begin{array}{l}\text { open internal bearing housing (I.B.H.) and fit on } \\
\text { crank case }\end{array}$ & 14 \\
\hline 6 & I.B.H. tightening on crank case & 22 \\
\hline 7 & I.B.H. torquing on crank shaft & 20 \\
\hline 8 & $\begin{array}{l}\text { crank shaft mounting on the hook and placed it } \\
\text { over engine }\end{array}$ & 45 \\
\hline 9 & crank shaft placed in the crank case & 23 \\
\hline 10 & I.B.H. stud fitment and tightening on crank case & 43 \\
\hline 11 & I.B.H. stud torquing & 13 \\
\hline
\end{tabular}

\begin{tabular}{|l|l|l|}
$\mathbf{1 2}$ & marking with marker & 2 \\
\hline $\mathbf{1 3}$ & centre bolt tightening & 9 \\
\hline $\mathbf{1 4}$ & Centre bolt torquing & 7 \\
\hline $\mathbf{1 5}$ & crank shaft tackle fitment & 33 \\
\hline $\mathbf{1 6}$ & indexing & 5 \\
\hline \multicolumn{2}{|l|}{ Total time } & $\mathbf{3 0 6}$ \\
\hline
\end{tabular}

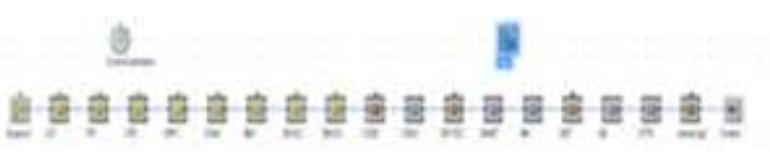

Figure 13: Single Transfer Line for Crank Shaft Fitment

Simulation times t:atew00000

Cunulated Statistica of the Parts uhich Be Orais Deleted

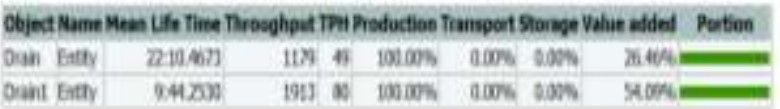

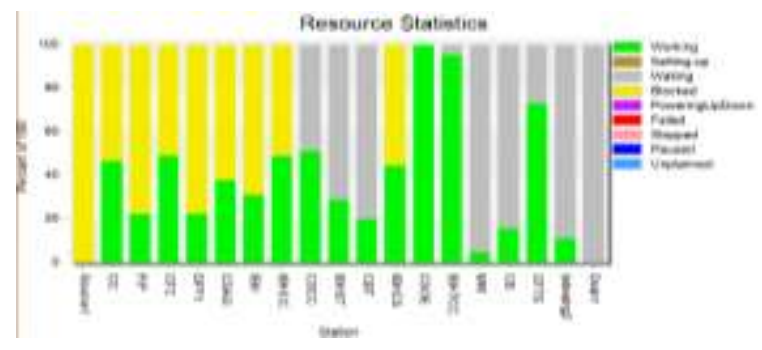

Figure 14: Chart of Single Transfer Line for crank shaft fitment

In a crank shaft fitment as per the simulation it is found that the total throughput of the day is 1913 and the some block and waiting are identify.

Table 3 Crank Gear Pressing

Station No. -3R(2) (CRANK GEAR PRESSING)

\begin{tabular}{|l|l|l|}
\hline S. No. & \multicolumn{1}{|c|}{ Operation 's Name } & $\begin{array}{l}\text { Time } \\
(\mathbf{s})\end{array}$ \\
\hline 1 & $\begin{array}{l}\text { Shift engine from pedestal mounting station to } \\
\text { the running line }\end{array}$ & 37 \\
\hline 2 & Balancing weight tightening with D.C. Tool & 100 \\
\hline 3 & Balance weight torquing & 100 \\
\hline 4 & Marking on balance weight & 10 \\
\hline 5 & 90 degree rotation to the block & 2 \\
\hline
\end{tabular}




\begin{tabular}{|l|l|l|}
6 & $\begin{array}{l}\text { Fit thrust washer \& crank gear on the crank } \\
\text { shaft }\end{array}$ & 42 \\
\hline 7 & Gear pressing on the crank shaft & 29 \\
\hline Total & $\mathbf{3 2 0}$ \\
\hline
\end{tabular}

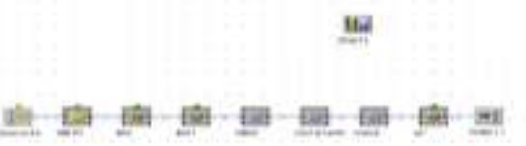

Figure 15 Single Transfer Line for Crank Gear Pressing

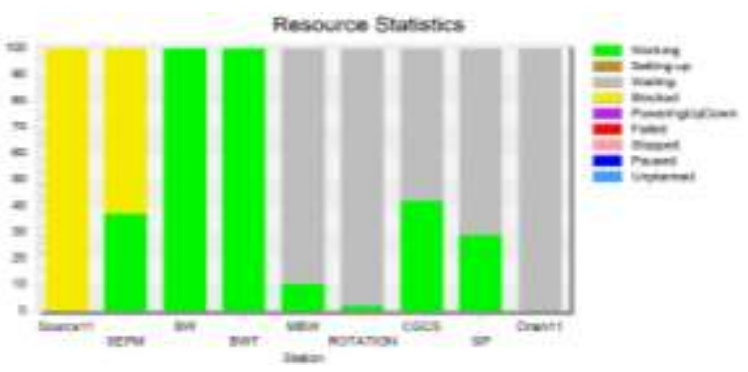

Figure 16 Chart of Single Transfer Line for crank gear pressing

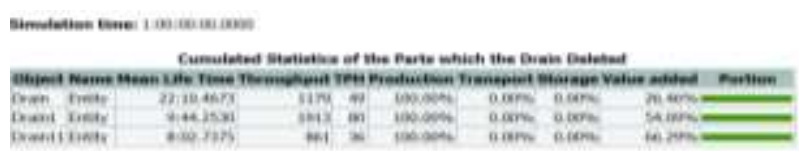

In a crank gear pressing as per the simulation it is found that the total throughput of the day is 861 and the some block and waiting are identify.

Table 4 Bearing Housing Fitment

\begin{tabular}{|l|l|l|}
\hline \multicolumn{3}{|l|}{ Station No. - 4L (BEARING HOUSING FITMENT) } \\
\hline $\begin{array}{l}\text { S. } \\
\text { No. }\end{array}$ & Operation & $\begin{array}{l}\text { Time } \\
(\mathrm{s})\end{array}$ \\
\hline $\mathbf{1}$ & Left pedestal picking & 10 \\
\hline $\mathbf{2}$ & left pedestal tightening & 32 \\
\hline $\mathbf{3}$ & crank shaft tackle de assemble & 9 \\
\hline $\mathbf{4}$ & bearing housing fitment & 26 \\
\hline $\mathbf{5}$ & bearing housing bolt hand tighten & 29 \\
\hline $\mathbf{6}$ & bolt tighten with Electronic torque wrench & 31 \\
\hline $\mathbf{7}$ & Oil seal fitment & 14 \\
\hline $\mathbf{8}$ & oil seal pressing & 32 \\
\hline $\mathbf{9}$ & Lifter guide picking & 14 \\
\hline $\mathbf{1 0}$ & lifter guide fitment & 17 \\
\hline
\end{tabular}

\begin{tabular}{|l|l|l|}
$\mathbf{1 1}$ & Clamp fitment and hand tighten & 22 \\
\hline $\mathbf{1 2}$ & $\begin{array}{l}\text { clamp tightening with electronic torque } \\
\text { wrench }\end{array}$ & 12 \\
\hline Total time & $\mathbf{2 4 8}$ \\
\hline
\end{tabular}

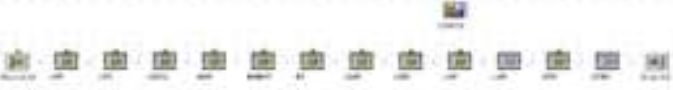

Figure 5.7 Single Transfer Line for Bearing Housing Fitment

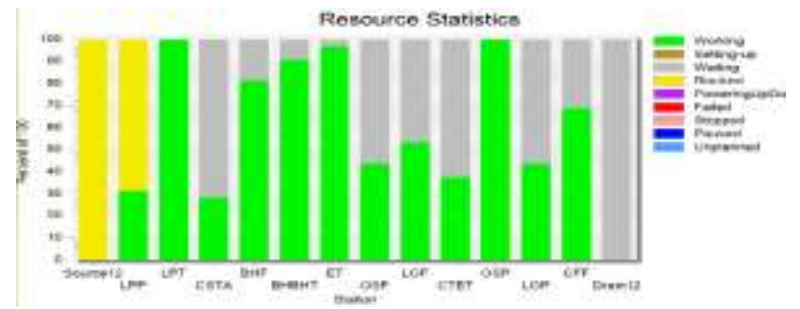

Figure 17: Chart of Single Transfer Line for Bearing Housing Fitment

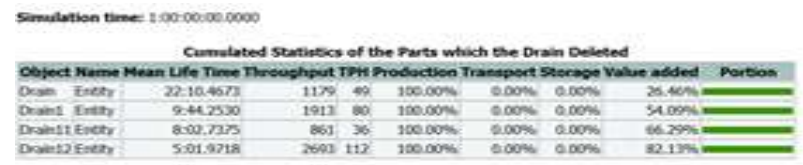

In a bearing housing fitment as per the simulation it is found that the total throughput of the day is 2693 and the some block and waiting are identify.

So to achieve the optimum results at same running cost there is some buffer is needed as shown in fig at last row in this production line the throughput is increase from the previous upto $24 \%$

Then to identify the optimum buffer size the experimental manager is created the check the capacity of buffer by using drain the output values are selected which show simtalk value as per the simens technology than the three simulation in run for each experiment and there is a predefined confidence level that is upto $90 \%$ then each experiment is done by the upper and lower limit of 5 to 50 at the increment of 5 once the experimental manager finish its process it generate the report as shown in the table as the output values shows show how many parts created form these results we observer the maximum throughout at the $\mathrm{n}$ number of experiment the highest throughout show the size of buffer.

Overview of all executed experiments, their parameterizations and the mean values of the target values. 


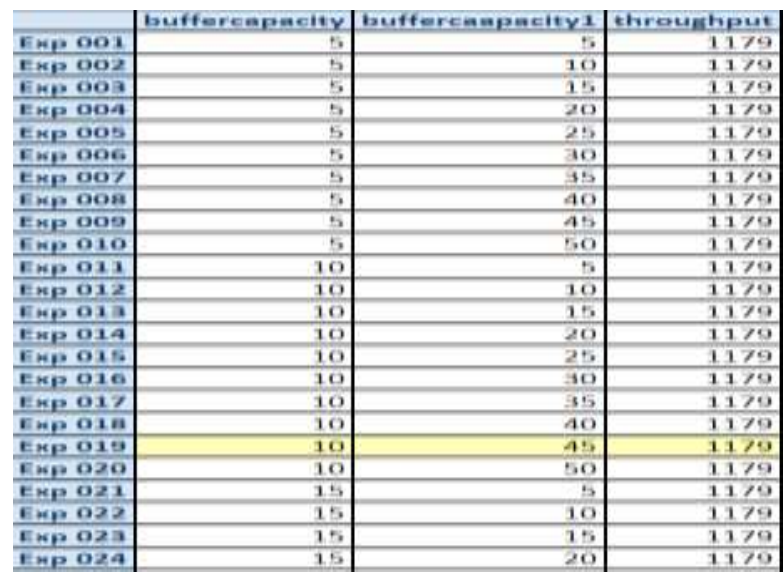

\begin{tabular}{|c|c|c|c|}
\hline Expars & 15 & 25 & 1270 \\
\hline$E=020$ & 15 & 30 & 1170 \\
\hline$E-p, 027$ & 35 & 35 & 1179 \\
\hline$F \approx p \quad 02 m$ & 35 & 40 & 1270 \\
\hline$F \propto p \quad 0 \geq 0$ & 15 & 45 & 1170 \\
\hline$E m 030$ & 15 & 50 & 1270 \\
\hline $5 \times p, 0>1$ & 20 & 5 & 1279 \\
\hline Fup as & 20 & 10 & 1370 \\
\hline$E x p 03$ & 20 & 15 & 1170 \\
\hline$F=p=0 \geq 4$ & 20 & 20 & 3170 \\
\hline$E x p$ oas & 20 & 20 & 1179 \\
\hline Exp 0 0 20 & 20 & 30 & 1170 \\
\hline$E=0,037$ & 20 & 35 & 1170 \\
\hline Exp ovas & 20 & 40 & 1379 \\
\hline Exp 030 & 20 & 45 & 1270 \\
\hline$E \approx 0,040$ & 20 & 50 & $11 \%$ \\
\hline$E=0.1$ & 25 & 5 & 1279 \\
\hline $5 \times p-042$ & $7=$ & 10 & 1170 \\
\hline$E$ Exp 043 & 25 & 35 & 1370 \\
\hline$E=p$ ona & 25 & 20 & 1170 \\
\hline Expous & 29 & 20 & 1170 \\
\hline$E=0.46$ & 25 & 30 & 1370 \\
\hline$E \approx p=047$ & 25 & 35 & 1270 \\
\hline Expouse & 25 & 40 & 1179 \\
\hline$E \approx p=040$ & 25 & $a=$ & 1179 \\
\hline Exp 050 & 25 & 50 & $11 \%$ \\
\hline$E=0$ os & 30 & 5 & $11 \%$ \\
\hline Exposaz & 30 & 10 & 3370 \\
\hline Exm oss & 30 & 35 & 1370 \\
\hline Exp 055 & 30 & 25 & 1179 \\
\hline Емр 056 & 30 & 30 & 1179 \\
\hline Exp 057 & 30 & 35 & 1179 \\
\hline Exp 058 & 30 & 40 & 1179 \\
\hline Exp 059 & 30 & 45 & 1179 \\
\hline Exp 060 & 30 & 50 & 1179 \\
\hline Ехр 061 & 35 & 5 & 1179 \\
\hline Exp 062 & 35 & 10 & 1179 \\
\hline Exp 063 & 35 & 15 & 1179 \\
\hline Емр 064 & 35 & 20 & 1179 \\
\hline Exp 065 & 35 & 25 & 1179 \\
\hline Exp 066 & 35 & 30 & 1179 \\
\hline Exp 067 & 35 & 35 & 1179 \\
\hline Exp 068 & 35 & 40 & 1179 \\
\hline Ехр 069 & 35 & 45 & 1179 \\
\hline Exp 070 & 35 & 50 & 1179 \\
\hline Exp 071 & 40 & 5 & 1179 \\
\hline Еяр 072 & 40 & 10 & 1179 \\
\hline Exp 073 & 40 & 15 & 1179 \\
\hline Exp 074 & 40 & 20 & 1179 \\
\hline Exp 075 & 40 & 25 & 1179 \\
\hline Exp 076 & 40 & 30 & 1179 \\
\hline Exp 077 & 40 & 35 & 1179 \\
\hline Ехр 078 & 40 & 40 & 1179 \\
\hline Ехр 079 & 40 & 45 & 1179 \\
\hline Ехр 080 & 40 & 50 & 1179 \\
\hline Exp 081 & 45 & 5 & 1179 \\
\hline Ехр ОВ2 & 45 & 10 & 1179 \\
\hline Exp 083 & 45 & 15 & 1179 \\
\hline Exp Osa & 45 & 20 & 1179 \\
\hline Exp OBS & 45 & 25 & 1179 \\
\hline Ехр ов6 & 45 & 30 & 1179 \\
\hline
\end{tabular}

\begin{tabular}{|l|r|r|r|}
\hline Exp 087 & 45 & 35 & 1179 \\
\hline Exp 088 & 45 & 40 & 1179 \\
\hline Exp 089 & 45 & 45 & 1179 \\
\hline Exp 090 & 45 & 50 & 1179 \\
\hline Exp 097 & 50 & 5 & 1179 \\
\hline Exp 092 & 50 & 10 & 1179 \\
\hline Exp 093 & 50 & 15 & 1179 \\
\hline Exp 094 & 50 & 20 & 1179 \\
\hline Exp 095 & 50 & 25 & 1179 \\
\hline Exp 096 & 50 & 30 & 1179 \\
\hline Exp 097 & 50 & 35 & 1179 \\
\hline Exp 098 & 50 & 40 & 1179 \\
\hline Exp 099 & 50 & 45 & 1179 \\
\hline Exp 100 & 50 & 50 & 1179 \\
\hline
\end{tabular}

\section{VI.CONCLUSION}

The primary goal of my project is to learn the standard procedure of 'Line Balancing'. I have been made to study cycle time of all the stations in the assembly line. This study shows that an unbalanced assembly line may generate significant capacity loss in a cumulative pattern, which requires a continuous waste elimination and balancing approach in production.

In order to achieve maximum gain over the current system in terms of reduced operational costs and resource utilization, the existing line should be re-organized such that,

1. Idle Time to be reduced on the station by shifting the operation from one station to another station.

2. Components to be relocated near the assembly stations.

By comparing both the assembly line layouts it was found that the proposed design has better and delivers good efficiency of the assembly lines. The results for both the layouts are taken to find the real time efficiency and manpower which also has a bearing on optimal working area for assembly lines. We can improve the efficiency of any manufacturing unit by applying improved technique and design methods. Good conveyor can improve the efficiency of plant Plant Simulation simulations are used to optimize throughput, relieve bottlenecks and minimize work-in-process. The simulation models take into consideration internal and external supply chains, production resources and business processes, allowing you to analyze the impact of different production variations. You can evaluate different line production control strategies and verify synchronization of lines and sub lines. The system lets you define various material flow rules and check their effect on the line's performance. Control rules are chosen from libraries and may be further detailed to model highly sophisticated controls. The Plant Simulation experiment manager allows you to define multiple experiments at one time, providing an efficient way to analyze and optimize your system. Based on user-defined parameters, Plant Simulation executes different simulation runs and provides you with the results of these experiments. Plant 
Simulation analysis tools allow for easy interpretation of simulation results. Statistical analysis, graphs and charts display the utilization of buffers, machines and personnel. You can generate extensive statistics and charts to support dynamic analysis of performance parameters including line workload, breakdowns, idle and repair time and proprietary key performance factors. At the click of a button, Plant Simulation's bottleneck analyzer shows the utilization of resources, thus indicating bottlenecks as well as underworked machines. Material flow may be visualized in a Shunky chart that, at a glance, shows transport volume in the context of the layout. Plant Simulation also generates a Gantt chart of the optimized production plans that can be modified interactively.

\section{REFERENCES}

[1] Borojevic, S., Jovisevic, V., Jokanovic, S. Modeling, simulation and optimization of process planning. Journal of Production Engineering, 12, 1 (2011) 88-92.

[2] Rajashekar Patil "Discrete Event Simulation for Increasing Productivity in Digital Manufacturing" DOI: 10.2139/ssrn.2105005 June 2012

[3] Olivier Martin, Sébastien Gebus, Alexandre Soulas and Esko Juuso, "production optimization on pcb assembly lines using discrete-event simulation", University of Oulu Department of Process and Environmental Engineering, Control Engineering Laboratory, 24, May 2004, ISBN 951-42-7372-9.

[4] A Gatsou, Xenofon Gogouvitis "Discrete event simulation for manufacturing system analysis: An industrial case study" July 2009

[5] B. FINEL, A. DOLGUI and F. VERNADAT, "A random search and backtracking procedure for transfer line balancing", International Journal of Computer Integrated Manufacturing, Vol. 21, No. 4, June $2008,376-387$

[6] Fatme Makssoud, Olga Battaïa \& Alexandre Dolgui "An exact optimization approach for a transfer line reconfiguration problem", Int J Adv Manuf Technol, (2014) 72:717-727 DOI 10.1007/s00170014-5694-x.

[7] Julia Siderska, "Application of tecnomatix plant Simulation for modeling production and logistics processes", Business, Management and education ISSN 2029-7491/ eISSN 2029-6169, 2016, 14(1): 64-73 doi:10.3846/bme.2016.316.

[8] M. Chorowski, P. Duda, J. Fydrych and J. Polinski, "second law analysis and optimization of cryogenic transfer lines", Advances in Cryogenic Engineering AIP Conf. Proc. 1434, 1927-1934 (2012); doi: $10.1063 / 1.4707131 \odot 2012$. 